\title{
THE DUBLIN
}

\section{QUARTERLY JOURNAI。 \\ OF}

\author{
MEDICAL SCIENCE.
}

MAY $1,1854$.

\section{PART I. \\ ORIGINAL COMMUNICATIONS.}

ArT. XI.-On Paralysis occurring during Gestation and in Childbed. By Fleetwood Churchild, M.D.'T.C.D., M.R.I.A., Fellow of the King and Queen's College of Physicians in Ireland, and Associate Member of the College of Physicians, Philadelphia, U.S., \&c. \&c. ${ }^{a}$

Having been much interested by a case of paralysis after delivery, to which I was called by my friend Dr. Duke, I was led to make some inquiry into the occurrence of the disease, not merely after delivery, but during gestation, and to examine the authorities within my reach, in order to collect from them all the information they contain; but I am sorry to say that my search has not been very fruitful in results. Bearing in mind that paraly tic affections may occur as a termination of convulsions, as, well as independently, I carefully looked over the principal obstetric writers; and in the works of Giffard, Ould, Exton, Smellie,Chapman, Pugh, Burton, Moore, Foster,Perfect, Osborn, Spence, Hamilton, Denman, Burns, Merriman, Blundell, Collins, Davis, Lee, Murphy, and Hardy and M'Clintock, $I$ have found no mentian of the disease. 1854.

* Read at a meeting of the Association of the College of Physicians, March 1, vol. XVII. No. 34 , N. s. 
Dr. Campbell has a short section on paralysis of the pelvic extremities, which, he observes, "may be either partial or complete; and in all the cases which I have seen is confined to one of the limbs. It must be owing to the long duration of the head in the pelvis, from disproportion and consequent injury to the pyriformes muscles, or great sacro-sciatic nerves. The partial variety is what we generally meet with, and in either, it is a protracted complaint, without the patient, however, in any instance that $I$ have seen, becoming permanently lame"a. Dr. Ryan observes, that " some women, after the easiest as well as after instrumental delivery, are attacked with paralysis of the lower extremities, which is generally attended with retention of urine. The disease usually disappears in a few weeks"b.

Dr. F. Ramsbotham states that "paralysis of one or both legs, in very various degrees, occasionally happens after labour; more frequently when the process has been tedious and painful; but sometimes, when it has been of ordinary duration, or even of unusual rapidity. It is not attended with cerebral affection, and is dependent on the pressure which the muscles and nerves have sustained during the passage of the child's head through the pelvis. There is pain or numbness both within that cavity and around the hip, and an inability to move the limb with freedom. It generally disappears by degrees within a few days; at other times it continues beyond the period the patient usually remains in bed, and compels her, when she rises from it, to use a stick or a crutch." Again, " hemiplegia, indeed, may appear after delivery, as well as at other times, but there will be particular symptoms, independently of the local affection, which are too well known to require mention from me here"c.

Dr. Dewees has given two cases of convulsions, followed by temporary blindness ${ }^{d}$; but this is the only reference to the subject in his works, or those of Dr. Meigs.

I have not been more fortunate in my search among systematic writers on diseases of women, for neither Leake, Hamilton, Blundell, Hall, nor Ashwell, makes mention of either paraplegia or hemiplegia.

I find as little notice of these affections in French or German obstetric works. I have examined the writings of Saccombe, Boivin, La Chappelle, Baudelocque, Maygrier, Gardien, Velpeau, Moreau, Chailly, and Jacquemier, of Carus, Jöerg, Wigand, and Busch, on midwifery; and of Nauche, Capuron, Gardien, Jöerg, and Siebold, on diseases of women, without hav.

- Midwifery, p. 406.

- Obstetric Medicine and Surgery, p. 548.
Danual of Midwifery, p. 661.

d Midwifery, p. 506 , 
ing been able to find an allusion to it. The recent work of M. Scanzoni, of Wurzburg, is the only one in which it is noticed. He has a chapter on paralysis of the lower extremities, in which, admitting that it may in some cases be owing to pressure, yet as it may not appear until some time after labour, and as a similar affection may attack the upper extremity, he considers that pressure cannot be the sole cause, but that it may be attributed to some more profound derangement ${ }^{\mathrm{a}}$. He has given a case which I shall quote hereafter.

This paucity of information in systematic obstetric works, it occurred to me, might be owing, not solely to the rarity of the disease, but partly to the opinion that the disease belonged more properly to the department of general medicine, and that, perhaps, I should find more information in works treating of the practice of physic generally, or of diseases of the nervous system in particular. I have, therefore, consulted such as are within my reach, but with very limited results. The disease, as connected with pregnancy or childbed, is not mentioned by Hasse, Rokitanski, or A bercrombie, but the latter distinguished observer has some observations so apposite to the cases which I shall relate presently, that I shall take the liberty of quoting them. He states, that an attack of paralysis mayb - " 1 . Be merely the prelude to the apoplectic, and may pass into it after a short interval. 2. The attack may, under proper treatment, pass off speedily and entirely, leaving, after a very short time, no trace of its existence. 3. The recovery may be very gradual, the use of the affected limbs being restored after several weeks or months. 4. The palsy may be permanent, \&c. \&c." And again, he remarks, that " the whole phenomena of palsy do indeed bear evidence that certain cases of it depend upon a cause which is of a temporary nature, and capable of being very speedily and entirely removed. We see hemiplegia take place in the highest degree, and yet very rapidly disappear; but the most singular circuinstance connected with certain cases of palsy is, that we occasionally see it continue without any improvement for many weeks or months, and then, from some change which entirely eludes our observation, take a turn for the better, and entirely disappear." Dr.Todd ${ }^{c}$ mentions the fact, that anæsthesia of the face sometimes occurs after parturition, and also that paralysis may occur, and that it is sometimes coincident with phlegmasia dolens.

Dr. Cooke, in his work on Nervous Diseases, does not treat

a Lehrbuch der Geburtshuife, p. 1000. b Diseases of the Brain, \&c., pp. 246, 248.

c Cyclopædia of Practical Medicine, vol. iii. p. 243. 
of paralysis in connexion with pregnancy or parturition, but he notices a curious fact, which is illustrated by one of the cases I shall detail, namely, that a patient with hemiplegia is sometimes unable to 'thter the exact word they wish, to express their meaning, either from ${ }^{b}$ forgetting it, or from a difficulty in pronouncing $i t^{\mathrm{a}}$.

Dr.Graves, in his admirable observations on the Pathology of Nervous Diseases; when treating of the centric or excentric origin of certain forms of paralysis, remarks: "I shall endeavour to prove, first, that paralysis (from whatever eansey) affecting one portion of the circumferential extremities of the nerwes, may also affect other portions of their extremities; secondily, that pain originating in one situation may produce a similar sensation in distant parts; and, thirdly, that convulsions, resulting from irritation in any part of the extremities of the nervous system, may' occasion a corresponding train of symptoms in other parts of the body"b. Although I think that these observations bear directly upon the affection under consideration, they were not so associated in Dr. Graves' mind, for he makes no allusion to paralysis occurring before, during; or after labour.

In Dr. Watson's Practice of Physic there is a very full and able account of the different varieties of palsy, but no mention of its occurrence in pregnancy or childbed; nor yet in the more recent special treatise of Dr. Copland.

I may further observe, that in none of these works is there any notice of the condition of the urine previous to or immediately after the attack. The only author who up to this period seems to have suspected a connexion between serious nervous affections and certain states of this secretion is Dr. Latham, who, after enumerating various diseases attended with or caused by albumen in the urine, says of the brain, "And some of its graver affections will come and go, and admit of a present relief, which is unusual where harm has befallen its own structure: convulsions and apoplexies appear and disappear, and yet are ultimately fatal, the chief concomitant circumstance which attracts our notice being albuminous urine"c.

Dr. Romberg, in his valuable work recently published by the Sydenham Society, has a section upon "paralysis depending upon the affections of the sexual organs"d, which is of such interest that $I$ trust a pretty long quotation will be excused. "The female sex," he observes, "offers peculiar opportunities

- Vol. ii. p. 10. b Clinical Medicine, by Neligan, vol, i. p. 501.

e Diseases of the Heart, vol. ii. p. 229.

- Diseases of the Nervous System, vol. ii. p. 390 . 
for the study of paralytic attacks connected with morbid conditions of the sexual system: they arise either from direct pres. sure of the distended uterus, or ovary, upon the nervous plexuses of the lower extremity, and are then only unilateral, and acecompanied by derangement of sensibility, as pain, numbness, or loss of sensation; or they are caused by a reflex influence upon the spinal cord, and then affect both sides of the body. $V$ eterinary surgeons have repeatedly met with the complication of paraplegia and metritis; Gelle $e^{a}$ quotes eleven cases of acute metritis in cows, which had followed calving; in all, the power of moving the hind legs was diminished, while sensibility continued unimpaired. Sewell publishes the sectio cadaveris of a cow attacked with paraplegia following calving; intense inflammation was found in the uterus and vagina. Ithen has communicated a few. cases of metritis in mares which was accompanied by inability to stand, and to raise themselves on their hind legs. Dx. Hunt has observed similar occurrences in women. Lisfrance details the case of a lady, aged 36 , who bad gradually been attacked with paraplegia, without any loss of sensibility. All the remedies applied on the assumption of a disease of the spinal cord remained unavailing. Lisfrane made a vaginal examination, and found the fundus uteri so much enlarged as almost to fill the pelvis; after using the iodide of potassium and iodine frictions for three months, and taking the waters at Barège, the tumefaction of the uterus was reduced, and complete recovery was obtained in two years.

"Paralysis of the lower extremities often supervenes during confinement and even after easy births, without pain having preceded or being associated with it; and the accoucheurs attribute it to compression of the sciatic plexus, and obturator nerve, for which there is $n \rho$ warrant whatever. . There would be more justice, in assuming that an accumulation of serops fluid had taken place in the spinal canal, resulting from disturbance of the circulation, as we find in tumours of the abdominal canity bist, morbid anatomy does not afford any propfs of the fact. No such condition, hipwever, is necessary, as de. monstrated by a case which recently came to my notice and

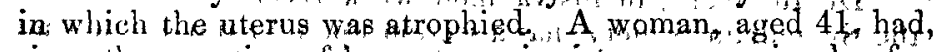
since the cessation of her catamenia six years previously, frequently suffered, from twitching of the inferior extremities,

a Journal Pratique, \&e, 1826.

b Veterinarian, vol. iv. p. 509.

c Nebel und Vix. Zeitschrift für die Gesam. Thierheilkunde, vol. iii.

a Sitanky, p.'z74!:

e Journal de l'Anat. de la Physiol. ét de Ia'Páchol rdu Système Nenrehx, 1843 , vol i. p. 154 . 
and for nine months past, motility had been diminished; there was a frequent tremor and sense of weight in the legs. The cutaneous sense of touch was dull in the feet, especially in the left, in which the tisease had commenced with lacerating pains. Retention of urine, alternated with eneuresis, especially at night. The upper extremities continued in the full possession of their vigour. No abnormity was discoverable in the spinal cord. Dr. Schöller, whose accurate method of exploration is well known, found that the vagina was much shortened, and that there was no portio vaginalis, only the transverse fissure of the uterus remained visible at the arch of the vagina, directed from before backward. The os tincæ was very soft, and the neck presented the usual hardness; it was evident that the sexual system had undergone a process of involution, as in an old woman. I ordered the alkaloid of the nux vomica, strychnine, in doses of a quarter of a grain, twice a day, and friction of the legs with the ethereal oil of turpentine; after continuing this treatment for three weeks, a favourable effect was experienced."

A friend very kindly undertook a tolerably extensive search among the periodicals, but, with two remarkable exceptions, nothing on the subject was found. These two exceptions were, a paper by Dr. Lever, of London, and one by Professor Simpson, of Edinburgh. With both of these gentlemen I have been in communication, and from both $I$ have received additional matter, a favour whose value has been doubled by their frank, kind manner of conferring it, and for which I take this opportunity of returning my warmest thanks.

Dr. Lever's cases of paralysis form part of an interesting series, illustrative of certain nervous affections of pregnancy; and in support of his conclusion that " pregnancy is occasionally associated with chorea, or convulsive movements; with paralysis of various parts of the body, of the extremities, and of the nerves of special sense; and with mania"k. The varieties of paralysis he describes are, amaurosis, deafness, hemiplegia, loss of power in both upper extremities, loss of power in the right lower extremity, \&c. \&c. I shall take the liberty of giving an abstract of these cases by and by.

Dr. Simpson's communication, published in the same year, consists of some observations made at the Edinburgh Obstetrical Society, from which I shall extract so much as relates to the subject before us at present. " 1 . Albuminuria, when present during the last periods of pregnancy and labour, denotes a great and marked tendency to puerperal convulsion. 2. AI- 
buminuria in the pregnant and puerperal state sometimes gives rise to other and more anomalous derangements of the nervous system, without proceeding to convulsions; and Dr. Simpson had, especially, observed states of local paralysis and neuralgia in the extremities, functional lesions of sight (amaurosis, \&c.) and hearing; hemiplegia and paraplegia more or less fully developed. ...." "5. Albuminuria and its effects are far more common in first than in later labours, and then constitute adisease which generally disappears entirely after delivery. But Dr. Simpson had seen one case commencing with sliglit blindness, but no œdema, and ending gradually in hemiplegia, where the palsy remained after delivery, and after the disappearance of the albuminuria. In another, amaurosis came on with delivery, and had been present for six months, when Dr. Simpson first saw her. She had no odema or other symptom of albuminuria, but in testing the urine, it was highly albuminous. 6. Albuminuria with convulsiors, \&c. occurring in any labour later than the first, generally results from fixed granular disease of the kidney, and does not disappear after delivery. 7. Perhaps, in puerperal convulsions, \&c., produced by albuminuria, the immediate pathological cause of the nervous lesion is some unascertained but poisoned state of the blood. Was there a morbid quantity of urea in the blood? In several specimens of the blood of patients suffering under puerperal convulsions, furnished by Dr. Simpson to Dr. Christison and Dr. Douglas Maclagan, these gentlemen had been unable to detect any traces of urea. Was the poisoning material caseine in morbid quantity or quality? The dependence shown by Gluge and others, of albuminuria upon stearosis of the kidney, makes this connexion worthy perhaps of some inquiry." "9. Sometimes hemiplegia supervened during pregnancy, without albuminuria, but this form did not seem to interfere materially, or very dangerously, either with the pregnancy or labour; the disease running its own usual course. In one case, Dr. Simpson had seen the patient gradually but imperfectly recover the use of the palsied arm after delivery. In another, no improvement occurred"a.

Let us now see to what the information we have obtained from these different authorities amounts. Very briefly, we find:-

1. That hemiplegia, paraplegia, or partial paralysis, may occur previous to, during, or some time after labour.

2. That by some authors, the paralysis, in paraplegia especially, is attributed to pressure upon the muscles or nerves, in

- Edinburgh Monthly Journal, October, 1847, p. 288. 
prolonged labour; but this is also denied, as the same disease follows easy labour, or occurs after the lapse of some days.

3. Paralysis may terminate convulsions or accompany them.

4. Paralysis may be the consequence of organic disease, or of effusion into or upon the brain or spinal marrow.

5. Paralysis may result from reflex action.

6. The palsy may depend upon temporary causes, and among auch canses albuminuria may be included.

7. Hentiplegia may run on into apoplexy, or it may pass off in a, few weeks, or sometimes more slowly. Paraplegia may: leavea temporary or more permanent lameness: the local pal. sies (amauxosis, deafness, \&o.,) generally last but a moderate time.

8. A nervous or hysterical paralysis may occur occasionally in the unimpregnated state, or during pregnancy, but that it seldom continues after delivery.

I shall now proceed to give a short abstract of such cases as I have been able to collect from authorities, or from my professional friends, or which I have seen myself. Among the former, I am indebted to Dewees, Scanzoni, Crosse, Beatty, Lever, and Simpson; and, among the latter, to Drs. Lever, Simpson, M'Clintock, Beatty, Forrest, Ireland, and Duke.

I shall first give those in which the paralysis occurred dur. ing pregnancy; then those in which it occurred at the time of labour; and lastly, those in which it followed parturition.

\section{I.-PARALYSIS OCCURRING DURING PREgNaNCY.}

Case I. ${ }^{a}$-Hemiplegia, partial.-Mrs. A., aged 26, has two children; was attacked with " numbness in her right arm, and a diminution of its power. The mouth is drawn slightly to the right side, and there is a feeling of occasional tingling, and sometimes numbness, in the left thigh, leg, and foot. This was when she was about two months pregnant. Under careful treatment these symptoms diminished, but she did not lose them until her confinement. Similar symptoms accompanied the next pregnancies. Suffice it to say, that $I$ have now attended this lady in four pregnancies, and with four children, she having borne six; that the same symptoms make their appearance very soon after pregnancy takes place; that they become modified by treatment, but are never removed until after delivery; that the period of their cessation has seemed to depend upon the nature and amount of blood lost during labour, \&c., \&c."

CASE II.-Paralysis of Right Arm and Hand.-S. M.,

a Dr. Lever, Guy's Hospital Reports, vol. v. p. 12. 
aged 38, married for nine years, had miscarried on two oceasions, and during the eighth month of pregnancy was attacked by a "tingling sensation in the palm of her right hand and fingers, which rapidly ran up the extremity to the shoulder and axilla, when she found herself unable to hold or feel her needle; the fingers were slightly flexed on the hand, the hand on the fore-arm, and the fore-arm on the uterus." Five days after the attack Dr. Lever saw her. "The right extremity was in the condition above described; the sensation of the limb appeared little, if at all, deranged; but she complained of a sensation of heat throughout its whole extent: her countenance was pale; there was no pain or heat in the head; her bowels had been freely opened on the day of my visit; her pulse was small, feeble, and $96^{\prime 2}$. Under the use of sulphate of zinc, with nutritious diet, \&c, she improved, but did not recover the use of her arms until after her confinement.

"GNaE III.-Paraplegia - " Is that of Eliza H., who was in Gny's hospital several times (I believe three) under the care of my late colleague, Dr. Ashwell. Immediately after hor sixth labour, which was perfectly natural, she felt a great numbness in her lower extremities, as well as weakness, but from these she gradually recovered. During her seventh pregnancy, about the third month, her lower extremities gradually became paralyzed, and this time she was unable to stand or walk, and was compelled to keep her bed. After her confinement she was carried into the hospital, and placed under Dr. Ashwell's care, when she perfectly recovered. On going out, she became pregnant with her eighth child, and paralysis did not come on until after labour"b.

$\mathrm{C}_{\mathrm{ASE}}$ IV.-Amaurosis.-Mrs.T., aged 31, soon after quickening of her fifth child, " whilst engaged in some plain needlework, suddenly felt a peculiar sensation in the cye-balls, and found, on opening the lids, that she could merely see the outline of objects, their centre being perfectly dark." "Her eyes were dark; the pupils were large, and contracted (though sluggishly) upon the stimulus of light; the eye-balls seemed to have in a measure lost their mobility, and to be inordinately fixed; the eyelids altogether, or nearly, covered the globes, for if they were not protected, she complained of a sensation of dryness and smarting." This state continued until her confinement; in a week afterwards there was an improvement which increased until after her return from the country: at the end of three or four months she could see as well as ever.

a Dr. Lever, Guy's Hospital Reports, vol. v. p. 14. b Ibid. p. 16. c Ibid. p. 17. 
Case V.-Deafness.-Mrs. S., aged 23, when about three or four months pregnant of her first child, noticed that her hearing was not so acute as before; and it was evident that, week by week, it was becoming more obtuse. "She was dispirited and pale; her tongue, when protruded, was tremulous, flabby, and indented; her pulse small and feeble; her appetite tolerably good; her bowels regular; her nights restless; and the irritability of her temper had increased." The deafness continued to increase, in spite of treatment, until after her labour, which was natural. "The day after, she said her hearing was better, so that by the time she went to church, she could hear as well as ever"a.

CASE VI.-Hemiplegia.-Mrs. P., aged $18 \frac{1}{2}$, in the seventh month of her first pregnancy, fainted, in consequence of some family disputes, and when she recovered "it was found that she was hemiplegic on the right side, as far as the upper part of the abdomen; no pinching, tickling, or any other irritation, caused any movement in the right lower extremity. On the following day she swooned again, and this was followed by an apparent loss of motion and sensation in the right upper extremity. Matters continued the same for three days, when the limbs suddenly regained their usual power. Speechlessness now ensued, which also lasted for three days, and was followed by loss of power in the right lower extremity as far as the knee." The symptoms improved, but continued until she was delivered. In a subsequent pregnancy she suffered from speechlessness for a fortnight, and after delivery she found she had lost all power of the lower extremities, but this she gradually regained ${ }^{b}$.

Cases VII., VIII.-Memiplegia.-In addition to the preceding cases, which $I$ have condensed from his paper, Dr. Lever, in a letter which $I$ have his permission to publish, writes: "I have since seen two cases of hemiplegia depending upon cerebral disease, in which gestation proceeded to the full time, labour progressed, and the patient recovered. The child of one was hydrocephalic."

Case IX.-Facial Paralysis, Partial._-"I know of one woman who had had two deliveries and is now pregnant. She counts her pregnancy by finding numbness and want of power on the right side of the face, with a sensation of "pins and needles' in her right hand. She recovers after delivery."

CASE X.- - Another lady has had eight children, and has always suffered in a similar way! "She has just aborted. Neither of these patients could nurse their infants."

\footnotetext{
b Dr. Lever, Guy's Hospital Reports, vol. v. p. 18 . b Ibid. p. 20.
} 
$\mathrm{C}_{\mathrm{ASE}}$ XI.-Amaurosis. - " In the course of this year (1853) I was requested to see a lady about thirty years of age, highlysensitive, nearly eight months pregnant, who was suffering from amaurosis in one eye, perfect, in the other the loss of vision was not so complete. She had had two fits, but not having the opportunity of meeting the medical attendant at my first visit, I did not learn their nature; however, by her appearance and her evidence, I was induced to suspect the presence of albumen in the urine. The medical man applied the usual tests, and found that this was the case; and as the vision became more and more impaired, the operation for the induction of premature labour was resorted to. Labour pains commenced twenty-four hours after the rupture of the bag of the.waters, and in twelve hours the child was expelled, still-born. Three weeks since, her husband told methat his wife could play agame of cribbage."

CASES XII., XIII.-Deafness. - "In two instances I have known the sense of hearing, sorely blunted during pregnancy, restored after confinement; but albumen was not to be detected after delivery. When the albumen has been found wanting, the acuteness of hearing has returned." Let me add, that Dr. Lever mentions that in every case of this kind in which he exa. mined the urine, he found it albuminous.

My friend, Professor Simpson, has kindly furnished me with the following notes of cases which have come under his observation:-

CaSE XIV.-Hemiplegia.-Mrs. distinguished physician, when nearly eight months pregnant, became slightly amaurotic (palsy of the fifth): this led Dr. Simpson to examine the urine, which he found coagulable. Before labour came on, hemiplegia gradually supervened. The patient recovered, to a certain extent, after her confinement; she is now able to walk about, but has not yet the complete use of the affected side. In a subsequent letter he mentions another case of great interest.

CASE XV.-Facial Paralysis.- " The lady is within a week or two of her third accouchement. Four days ago, after feeling unwell, she felt a stiffness in the right side of her face, preceded by pain in the back of the head. The stiffness soon assumed all the usual symptoms of paralysis of the portio dura. When I saw her to-day, the face was much disfigured, particularly when smiling; she could not close the right eye, \&c.; and, in addition, there appeared a want of sensation about the cheek, nose, and lips, as if the sensitive branches of the fifth were also affected. The eyelids, but especially the right, were swollen and oedematous, but there was no odema of the hands or feet, 
or elsewhere. The pulse was very slow and weak. She was super-sensitive to sounds, light, de.: but the point that will in: terest you is this, that on testing the urine, I found it become very opaque and thick, on boiling." "I have seen a number of instances of local paralysis, particularly of the eyes, in connexion with albuminuria, but not until the present case, any example of paralysis of the seventh pair."

CAsE XVI.-Hemiplegia.-He adds, "Since writing to you, I have seen a patient who became hemiplegic six years ago, with her first child, and who has only imperfectly recovered the use of the affected side. From the symptoms nerompanying the attack, it was probably another instance of this result from puerperal albuminuria."

The following cases occurred in the practice of Dr. Crosse of Norwich:-

Case XVIT._Hemiplegia._." Mrs. _- was delivered of twins in May, 1844; a feeble, slender woman; had paralysis of the left side of the face before she married, which always remained; also the right became paralyzed after her labour, under a reducing diarrhœa, but this was recovered from. In the course of this year (1846) her paralysis of left side increased; she emaciated greatly; during these unfavourable changes there were sickness and indications of pregnancy. In June she had become so feeble as to take to herbed-room, and after some weeks could scarcely get out of her bed to have it adjusted. She passed her water only once in twenty-four hours, and at length had great difficulty in speaking and in swallowing,-all signs of her increasing paralysis or increasing disease of the brain." "She sunk in powers and bulk as pregnancy advanced; at the end of September could swallow only liquids and was much troubled with the mucus, which she could neither swallow nor expel by the mouth; very threatening paroxysms of suffocation were produced by this. In the beginning of October, she was evidently sinking fast, relieving us from the fear of delivery at fill time, which she could not have survived"a. She died October 12, but no post-mortem examination was made.

CAsE XVIII.-Hemiplegia.-_"Mrs. P., aged 42, mother of several children, six years ago had a slight paralytic stroke when pregnant, but went on to the full term of utero-gestation and recovered. "Coin plained of nubibness of right Teg'and arm

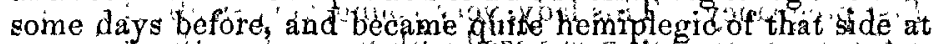

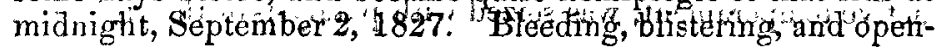

a Cases in Midwifery, \&e., by J. J. Crosse, M.D., F.R.S., p. 162 . 
ing medicine, employed, The liquor amnii began to dribble a few hours afterwards, and she was observed to strain as if in labour now and then, though she said she had no pain. In twenty-four hours a child between six and seven months was bopm dead, and the placenta followed. Although she strained, she did not appear to have the usual severe pain from the action of the uterus, and only called out at the last few pains when the child was passing through the os externum. Sept. 5 th. She remains hemiplegic, but in all other respects seems doing willa

CASE XIX-Hemiplegia.-Mrs. B., aged 27, was seized with hemiplegia a month before delivery, she recovered considerably before labour came on, on the 17th of May. "On the 9 gh of October she had slowly recovered almost the entire use of the limbs, but is thin, and feeble in mind as, well as body: In 1845 she wasqgain confiped withopt any paraly tic

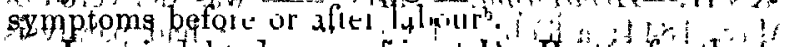

I and indebled to pyy friend Ir. Beatiy for the two following cases:-

Case XX.-Facial Puralysis.-Oct 1st, 1850. Mrs.

first pregnancy. This young lady expected her confinement about the end of this month, and was very much shocked, an going to dress herself this morning, to find her face crooked; she had no notice of the paralysis that seized the muscles of her face, and her first knowledge of it proceeded from seeing herself distorted in the looking-glass. I was sent for, and found the mouth drawn very much to the left side and the muscles on the opposite side flaccid and powerless; the tongue on being protruded was turned to the right side; she had some headach, and was very much frightened; pulse 98 and small ; leeches were applied behind the right ear, and after free purgation she was quickly brought under the action of mercury. Leeches were sevcral times applied in the same situation, followed by blisters, under which treatment the paralysis of the side of the face gradually diminished, and in less than three weeks it had quite disappeared. She was confined on the 21 st of the month. Her labour was easy, of eight hours' duration, and the child, a girl, was born alive and healthy. The urine was not examined. This lady has had two children since, and suffered no deviation from the healthy state in either pregnancy.

CASE XXI.-Hemiplegia.-August 8, 1844. Mrs. _-, first pregnancy. This lady, very young, very small, of a lively active temperament, was seized with paralysis of the right side

" Cases in Midwifery, \&c., by J. J. Crosse, M.D., F.R.S., p. 163 . b Ibid. p. 164. 
of the body, in the middle of the night, just three weeks before her confinement at the full period. The attack commenced with a fit resembling epilepsy or convulsive hysteria. When I saw her the next day she could not speak intelligibly, and had very little power over the right leg and arm. Her face was flushed. She complained much of headach, and was very irritable. Her pulse was 98, small and weak. Leeches were immediately applied to the temples, and the bowels were well freed as soon as possible, a large quantity of dark fæces being expelled. When this was effected, she was rubbed with mercurial oin tment, and leeches were again applied to the temples and behind the ears, followed by blisters to the nape of the neck and behind the ears. She was quickly brought under the influence of mercury, and severe salivation ensued. The power over the limbs soon began to return, and were it not for the severity of the action of the mercury on the mouth, she could have spoken. She recovered perfeetly in a fortnight, and was able to walk about and use her legs and arms. Her mouth continued very sore until her delivery took place. Her labour was an easy one, lasting only six hours, when a fine healthy girl was born. This lady had no swelling of the limbs nor any other premonitory symptoms of a convulsive attack. The urine was not examined. She has borne three other children since without any unnatural occurrence.

CASE XXII._- Partial Paralysis of Right Side.-My friend, Dr. M'Clintock, has favoured me with the following case:-

"A lady, of healthy constitition, but nervous temperament, was suddenly seized with numbness, coldness, and partial loss of power of the right leg and arm, when in the last month of her fourth pregnancy. She was immediately put to bed, and the limbs well chafed with spirits. I saw her very soon after the attack, and found her in a state of great alarm and nervousness. Neither pain nor vascnlar fulness of the head was present; nor had she suffered from any symptom usually regarded as indicative of cerebral congestion. In the course of an hour she lost the unpleasant sensations in the limbs, and completely regained the power of them. The following day her only source of complaint was an unpleasant tingling in the ring and little finger of the right hand, and at times also in the right side of her tongue and lips. In the course of the next three weeks she had occasional returns of these anomalous sensations in the leg, arm, and tongue, but less often in the leg than in the other parts. Once or twice she complained of her forehead and the roof of her mouth being similarly affected. On the 11th of August (1849), she was confined, and had a 
short and easy labour, and a most favourable convalescence. On the fourth day there was a return of the numbness and coldness, \&c., as before, in the right leg, side, and arm. Between this date and the 1st of October, when her child, which she had been nursing, died, seldom more than three or four days passed without a visit from her troublesome complaint. It lasted about an hour, and was generally accompanied by a considerable flow of limpid urine. On more than one occasion I observed that the temperature of the affected limb was lower than that of the other; once, but only once, both legs were affected. Dr. Chas. Johnson saw this lady with me on Sept. 13 , and agreed with me in thinking that her symptoms were of a purely nervous kind. Menstruation came on a few wceks after the death of her infant; nevertheless she continued to be tormented with this deranged sensation of the right side of the body. In the middle of December she went by our advice to the country, and returned home again in six weeks, wholly and entirely free from her complaint, after its having persisted for five months under the varying conditions of pregnancy, the puerperal state, lactation, and menstruation.

\section{II.-PARALYSIS DURING AND AF'TER DELIVERY.}

CASE XXIII--Amaurosis.-Mrs. - aged 26, was scized in labour of her first child, September 9, 1811, and was soon after attacked with convulsions. The fits were frequent and violent, and continued less frequently after delivery, which was completed by the forceps; she was bled largely; blistered; cold applied to the head, \&c.; but she remained insensible forty-eight hours after delivery, after which she gradually recovered. "She was left completely blind for two weeks; she then began to see imperfectly, but was six weeks before she could distinctly discern objects" sions, related by the same author, the sight, especially of one eye, remained for some time imperfect.

CASE XXIV.-Amaurosis.- "Mrs. C., first pregnancy; under difficulties and depressed spirits; under thirty years of age; labour began with a convulsion; eyesight and sensibility lost; pupils greatly dilated. I was called in in consultation; the os uteri was much dilated; delivery effected by forceps. Bleeding and blistering being freely practised, the convulsions ceased; eyesight, quite lost for several days, atlength returned, and there was perfect recovery"b.

a Dewees' Compendious System of Midwifery, p. 505.

b Crosse's Cases in Midwifery, \&c., p. 155. 
CAse XXV.--Hemiplegia.-I am indebted to Dr. M.Clintock for the following:- "This case occurred shortly before my leaving the hospital in the year 1847. E. D., aged 36 , was delivered of a healthy boy, her third child, after an easy labour of about four or tive hours' duration. Paralysis of the right arm and hand came on in the course of labour, and was wholly unattended by convulsion or any cerebral affection. She recovered the effects of her accouchement most satisfactorily, and could not be prevailed upon to remain in hospital beyond the eighth day (the usual time for the patients to return home) although she had but partially regained the use of the affected limb. During the seven days she remained under observation the treatment employed was at first warm stimulating fomentations to the arm, and afterwards blistering along the course of the brachial nerves, together with active purgatives. A very marked improvement took place under the use of these means, but the ultimate result of the case I do not know."

CASE XXVI._Paraplegia .-."In the month of December 1850 , M. J., aged 32 , an unmarried servant, was admitted into the Wurzburg Lying-in Hospital. She had previously been $t$ wice contined after natural labours, the last time in July, 1848. Eight days after this last confinement, she caught cold as she was washing in water up to her knees. Two hours afterwards she was attacked with symptoms of paralysis of the lower part of the left leg, which in the course of some days extended to the left thigh, and after two or three weeks to the right leg below the knee. At this time also the movements of both upper extremities were somewhat difficult, yet, though the patient could neither stand nor walk, she could still employ her hands in knitting, sewing, \&c. In the month of May, 1850 , conception again took place, accompanied by an increase of the palsy, without any diminution of the sensibility of the affected parts in the course of the disease. On the other hand, the deficiency of nutrition in the muscles of the forearm and legs was remarkable." Labour set in January 28,1851 , and after a considerable time she was delivered of a healthy child. She recovered well, and the paralysis seemed to diminish slightly from the fourth to the tenth day. Local bleeding, - blistering, electricity, strychnia, and ergot, were tried without material benefit, and she remained, a year and a half later, much in the same state as when she left the hospital.

CASE XXVII.-Paralysis of Right Leg.-The following

a Scanzoni, Lehrbuch der Geburtshïfe, p. 1000. 
oase tras been pablished by Dr. Beatty". "Anne Kiernan, aged twenty-one, delivered of her first chitd, November 26, $\mathbf{1 8 3 6}$, aftera labour of seven hours; infant born alive. Nothing remarkable occurred during labour or afterwards, until she complained: on the second day that she could not move her right leg and that it felt benumbed and dead. On examining the limb, no swelling nor pain could be discovered at any part that could indicate the approach of phlegmasia dolens; on the contrary, the sensibility of the limb appeared considerably lessened. Frietions with warm turpentine were ordered to the limb, but without any effect upon the condition of the part. At the end of a fortnight, finding that no improvement had taken place, a course of blisters along the line of the sciatic nerve was commenced, beginning above and going downwards. This plan, together with attention to her general health, had the effect of gradually restoring the power of the litinb. In a month she was able to walk across the ward with the assistance of a stick, but even yet the leg was dragged along with difficulty, iand when carried forward, the foot hang loose and vacillating, the toes pointing to the ground. In another month, she had regained considerable power over the muscles, her progression was much more firm and steady, and the sensibility of the limb was almost entirely restored. She continued to improve until the month of February, at which time she was walking about nearly well, and preparing to leave the hospital, when puerperal fever made its appearance in our wards." She was attacked by pericarditis, and died in about a week.

CASE XXVIII._Paralysis of the Left Leg".- "In the month of February, of the present year, 1851, a woman, aged 33, applied at the Polyclinique: on the 25th of January she had been delivered of her third child by the forceps; after a heavy labour, which had lasted twelve hours. During parturition she suffered from painful spasms of the left leg, and on the following and subsequent days, after she had left her bed, complained of lassitude, difficulty of walking, and diminished sensibility of the left foot. The examination showed that the sensibility of the left leg and thigh was normal, but that it was deadened on the dorsum and in the sole of the foot, so that the patient could not distinctly feel the hand when passed over it, or the ground when she put down her foot. The diminution of motility was betrayed by a laborious dragging of the leg in walking, and by

\footnotetext{
a Second Repprt of the New Lying-in Hospital ; Dublin, Joupnal, IFins Series, 461. xii. p. 304 .

- Romberg on Diseases of the Nervous System, Sydenham Society's Edition, vol. ii. p. 390 .
}

VoI. XVII. No. 34 , N. s. 
the difficulty with which she executed all the movements. The veins were varicose, and the uterus had remained prolapsed after delivery. A purgative was ordered, followed by friction with oil of turpentine and the internal exhibition of the spirituous extract of nux vomica, commencing with half a grain and increased to one grain three times a day. The result was so completely satisfactory, that the motility and sensibility were entirely restored, and on March 3rd the patient was discharged cured."

CASE XXIX--Hemiplegia.-For this case I am indebted to Surgeon Forrest. Mrs. H., aged 29, was confined of her second child on Friday, June 10,1853, after a natural labour of about five hours, the second stage being short. Considerable hemorrhage occurred after delivery, producing fainting, \&c., when Mr. Forrest was called in consultation. By means of a compress beneath the binder, and the application of cold, the discharge was controlled, and the patient progressed favourably, with abundance of milk, and the lochia natural, until Tuesday, June 14, when the lochia ceased without any apparent cause, and without uneasiness of any kind until Friday, June 17th, the eighth day after her confinement, when she was seized with paralysis of the right leg and arm, without headach or any other premonitory symptom. The muscles of the face were unaffected, the sight and speech were perfect, the pupils natural, and the intellect intact. On the following morning, June 18, she had a severe attack of convulsions, which affected the entire body, and the paralyzed extremities as well as the others, after which Mr. Forrest found her in a state of stupor. She had eight fits on this day. On Sunday she continued in a state of stupor, from which, however, she could be roused, and on this day also the convulsions recurred, though rarely, after which they ceased altogether. The pulse was quick, the intellect before and after the convulsive attack was clear, the speech perfect, the eyes natural, the sensibility of the paralyzed limbs unaltered, but the motor power entirely lost. After the convulsions she complained of headach, but this gradually ceased, and she recovered by degrees the use of her arm and leg in about two months. No external cause could be discovered for the attack; she had neither anxiety nor shock, was in good health previous to labour, and was neither liable to headach nor hysterical attacks. The hemorrhage after labour precluded blood-letting, so that the treatment consisted chiefly of counter-irritation by mustard cataplasms, turpentine and assafotida enemata, four-grain doses of camphor every second hour, purgatives, \&c. On Saturday, June 18, Mr. Forrest had 
the benefit of Dr. Montgomery's assistance in consultation. The patient is quite well at the present time.

CASE XXX.-Hemiplegia.-The following case, which also occurred after hemorrhage, is related in a letter from Dr. Ley to Sir Charles Bella : "Mrs. W. was delivered by a midwife at Kilburn. The labour was easy, but followed by profuse hemorrhage upon the separation of the placenta from the uterus. She revived from the state of exhaustion immediately consequent upon the loss of blood, but at the end of about three or four days became feverish, and complained of severe headach; for a week, however, she had no other assistance than that of the midwife. At the end of that time (about ten days after delivery), the headach continuing, and being now accompanied with some degree of ' numbness on one side,' I was requested to see her. I found her labouring under severe headach, not confined to, but infinitely more violent upon one side than the other, and occupying the region of the temporal and occipital bones, above the mastoid process, and attended with considerable pulsation. Upon one side of the body there was such defective sensibility, without, however, corresponding diminution of power in the muscles of volition, that she could hold her child on the arm of that side so long as her attention was directed to it; but if surrounding objects withdrew her notice from the state of her arm, the flexors gradually relaxed, and the child was in hazard of falling. The breast, too, upon that side partook of the insensibility, although the secretion of milk was as copious as in the other. She could see the child sucking and swallowing, but she had no consciousness, from feeling, that the child was so occupied: turgescence of that breast produced no suffering, and she was unconseious of what is termed the draught on that side, al though that sensation was strongly marked in the other breast. Upon the opposite side of the body there was defective power of motion, without, however, any diminution of sensibility. The arm was incapable of supporting the child; the hand was powerless in its gripe; and the leg was moved with difficulty, and with the ordinary rotatory movement of a paralytic patient; but the power of sensation was so far from being impaired that she constantly complained of an uncomfortable sense of heat, a painful tingling, and more than the usual degree of uneasiness from pressure, or other modes of slight mechanical violence. Medicinal agents, including bloodletting, general and local, blisters, purgatives, \&c., directed, first by myself, afterwards by Dr. P. M. Latham, to whose care I di- 
rected her in the Middlesex Hospital, were of little avail, and she left the hospital scarcely, if at all, benefited. At the end of a few months she again proved pregnant. Her delivery at the full time was easy, and unaccompanied with hemorrhage or other formidable occurrence; but at the expiration of about ten days she complained of numbness on both sides. The articulation was indistinct; she became more and more insensible, and sunk completely comatose. Upon examination of the body, no positive disorganization of the brain could be detected. The ventricles, however, contained more than the usual serum; and there were found, more especially opposite to the original seat of pain, thickening and increased vascularity of the membranes, with moderately firm adhesions in some parts; in others an ap. parently gelatinous, transparent, and colourless deposit interposed between them. Such is the outline of a case which I have been in the habit of quoting in my lectures as an illustration of one of the pathological conditions which I have repeatedly observed as a consequence of great and sudden loss of blood, and as a proof that it is a state of local congestion, allied if not amounting to actual inflammation."

Case XXXI.-Paralysis of Face and Arm.-Mrs. S., aged 43, was confined of her thirteenth child (all of whom are living) in June, 1844. Her labour was perfectly natural, neither preceded, nor accompanied, nor followed by any unusual symptom, until the seventh or eighth day: in the evening of which day, when quietly talking with her husband, she suddenly commenced exclaiming," Conveniency, conveniency, conveniency." Upon attention being directed to her condition, the mouth was observed to be quite drawn to one side, and complete paralysis of one arm existing. The leg of the same side was not affected. She was not nursing; the lochia were quite natural, and the bowels free. When Dr. Duke first saw her, the only additional symptoms he noticed were, a very quick pulse, and some difficulty of articulation. Cold to the head, aperients, and slight mercurialization, were the remedies employed, and they were successful, for she recovered the use of the arm and the power of speech in a fortnight. The quick pulse continued for some months, together with a certain amount of indistinctness of vision, for which she came to town, and I saw her, in consultation with Dr. Jacob and Dr. Duke. We advised counter-irritation, and a tonic treatment, under which she recovered perfectly.

CASE XXXII.-Hemiplegia.-Mrs.K., aged about 38, was delivered of her fifth child, September 15 , after a very easy labour. She was a woman of a very fragile constitution, and can 
hardly be said to have ever recovered from the inanition caused by incessant vomiting in a former pregnancy. She had not suffered, however, from headach or giddiness, and her stomach and bowels were in pretty good order during this pregnancy: neither had she any oederna or other local complaint. On September 16 and 17 , and up to noon of September 18, she continued quite well. The lochia were natural, and there was a sufficient secretion of milk. At noon, September 18, I was sent for, as they thought that she did not seem well, and $I$ found her hemiplegic on the left side. She was not, and the nurse believed that she had not beeninsensible, and she could speak pretty well, although her mouth was drawn to one side. The motor power of the arm and leg entirely lost, but the sensibility not impaired; pulse 120. A few leeches were applied to the temples, and the head was shaved and blistered: the bowels were too irritable to bear mercury. By these means, and a repetition of the blister, and afterwards the insertion of a seton in the arm, she seemed, much relieved. She remained perfectly intelligent, spoke well, gradually acquired the power of moving the leg, and, in a less degree, the arm; her face had recovered its natural expression, and ceased to be drawn to one side; the appetite was good, and the bowels regular; the only symptom which made me uneasy was the quick pulse, which never lell below 100. October 2 nd. She felt quite well this morning; as the bowels had been confined, she took a pill last night, and when it acted, she got up to the night-chair; whilst sitting there she became very faint, and never afterwards rallied. She died at 8 P.M., of the same day, without any increase of paralysis, without coma or stertor; in short, without any new symptom. No post-mortem examination could be obtained.

Case XXXIII.-Facial Paralysis.-Dr. Ireland has fur: nished me with the following record of three cases in one family. Mrs. O., aged 34, was confined of her fifth child, November 28, 1853 , and at the end of December was attacked by paralysis of the right side of the face, indistinct vision, ptosis of the right eyelid, \&c. Under the influence of leeching, blistering, and mercury, she recovered. Her mother had a similar attack after her confinement, which proved fatal; and her sister had suffered from paraplegia for years, which always increased after her confinements until her death.

CASE XXXIV._Hemiplegia.-Mrs. A., aged 26, was confined for the fourth time on Saturday, November 12, 1853, after a labour of two or three hours, the second stage being under one hour. She had enjoyed excellent health during pregnancy; had no headach or derangement of the stomach or bowels, no odema; nor was she subject to nervous or hysterical attacks. 
She was neither plethoric nor anemic. After her confinement she recovered, without a single drawback up to the seventh day, November 18 th, on which day, at 9 A. M., after speaking to the nurse quite composedly, but without making any complaint, she became insensible, with some twitchings of the face, but without any other convulsive movements. The insensibility lasted but a few minutes, but when she recovered she was found hemiplegic on the right side, with some difficulty of speaking. These symptoms gradually diminished, however, and at 3 P.M., when Dr. Duke requested me to see her, she could move both leg and arm, and grasp my hand firmly, and speak quite intelligibly. She was quite intelligent, but there were some words which she either could not pronounce or could not remember, although she recognised them when mentioned, and assented, nor could she put out her tonurue freely. She said that she had no pain in the head, or anywhere else; the eyes were clear and bright, the pupils well dilated, and amenable to light, which, however, caused her no annoyance. The pulse was 140 , small, thready, and fluttering. There was a slight degree of tenderness in the right iliac region, which disappeared soon after; the lochia were abundant, natural in appearance, and free from unusual odour; and she had plenty of milk. After very minute inquiry, neither Dr. Duke nor I could detect any cause for the attack. Dr. Duke had applied six leeches to the forehead; had given moderate doses of blue pill and opium, which were continued; and had applied sinapisms to the legs, and a blister to the nape of the neck. She continued pretty much in the same state during the day, but in the evening she had another attack of paralysis, accompanied by very slight twitchings of the arm, after which the loss of power was much more complete, although she retained perfect sensibility throughout.

November 19, 10 A. м. She slept at intervals during the night, pulse 140; small and weak. She can still move the leg a little, but the arm scarcely at all; her speech is thicker, and the difficulty of getting out certain words increased; but she shows that she understands everything that is said. The bowels have been moved, and the bladder emptied; but, from the difficulty of moving, she passes all under her, though not unconsciously. The same remedies were continued, the head shaved and blistered, and chicken broth allowed.

November 20, 10 A.M. In much the same state as yesterday, except that her pulse has improved in strength and volume, and is only 120. She has no pain at all, is quite intelligent; the expression of her face calm and easy; she cannot move the arm, but it is quite sensitive; the leg she moves a little. The bowels were moyed, and the urine passed. We had this day 
the advantage of Dr. Stokes' assistance, and as he concurred in our plan of treatment, the pills of mercury and opium were continued, another blister applied, and a mixture of ammonia, in infusion of orange peel, ordered.

November 21, 10 A. M. Dr. Montgomery visited her. with us this day; we found the paralytic affection in the same state as yesterday, but she seemed not quite so well, in consequence of having passed a slecpless night, and from the bowels having been acted on too freely by the mercury. Pulse 120, weak, but fuller and more steady than they were two days ago. Neither Dr. Stokes nor Dr. Montgomery was more successful than we had been in detecting the exciting or the pathological cause of the attack. The pills were ordered to be omitted, and a ohalk mixture, with a few drops of laudanum, substituted. Another blister was applied to the head.

November 22, 10 A. м. Our patient seemed better this morning, more lively and intelligent; she can move the leg more, but the arm and hand are quite powerless; the bowels are more quiet, and she takes a little food well. Partly from her inability to use the bed-pan, and partly from her passing both urine and freces together when she did use it, we had no opportunity of examining the former until to-day. The nurse had always told us that it appeared natural, but this day we procured a quantity, which I brought away for analysis. Unfortunately, the cork came out of the bottle, and all was spilled except about half an ounce. This, though insufficient for an accurate quantitative analysis, was enough to show the presence of a large proportion of albumen, with epithelial scales, pus corpuscles, and the urates of ammonia and soda.

Further visits on my part were unnecessary, but Dr. Duke was kind enough to furnish me with specimens of the urine passed in the nights of November 23rd, 25th, 26th ; and my intelligent young friend, $\mathrm{Mr}$. Charles Leet, has given me the follow. ing careful analysis of each.

No. 1.-Nov. 23. Urine, pale-yellow in colour, faint, peculiar odour, feebly acid reaction. Specific gravity, 1028.500.

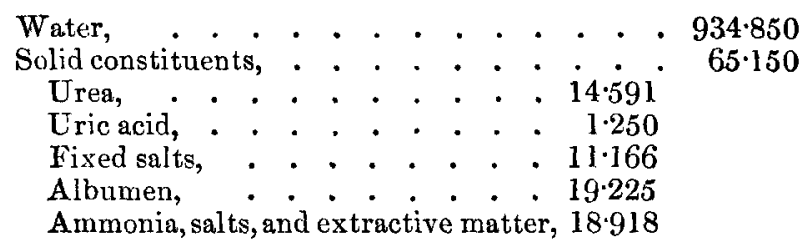

Amount in 1000 parts of urine, $\overline{65 \cdot 150}$ 
No. 2.-Nov. 24. Physical characters the same as the last, but with a much smaller sediment. Specific gravity, 1024-250.

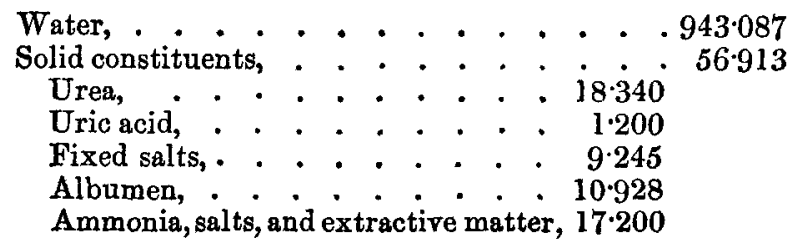

\section{Amount in 1000 parts of urine, 56.913}

No. 3.-Nov. 26. This specimen was of a deeper yellow colour, and had a stronger reaction. Specific gravity, $1014 \cdot 500$.

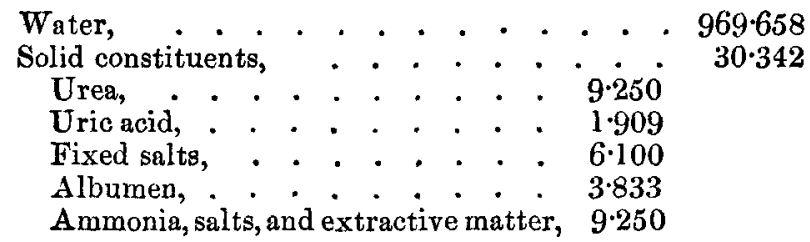

$$
\text { Amount in } 1000 \text { parts of urine, } \overline{30 \cdot 342}
$$

The following Table will afford a comparative view of each specimen with the others and with the average standard in health. As the quantity passed in twenty-four hours could not be ascertained, the normal quantity, $30 \mathrm{oz}$, has been assumed:-

\begin{tabular}{|c|c|c|c|c|}
\hline & $\begin{array}{c}\text { Normal } \\
\text { Average. }\end{array}$ & $\begin{array}{l}\text { Specimen } \\
\text { No. } 1 .\end{array}$ & $\begin{array}{l}\text { Specimen } \\
\text { No. } 2 .\end{array}$ & $\begin{array}{l}\text { Speciment } \\
\text { No. } 3 .\end{array}$ \\
\hline Amount of urinein twenty- & & & & \\
\hline$\underset{\text { Specific gravity. }}{\text { four hours, }} \cdot$. $^{\prime} \cdot$. $^{\prime}$ & $\begin{array}{l}30 \mathrm{oz} . \\
1019\end{array}$ & $\begin{array}{l}30 \mathrm{oz} \\
1028\end{array}$ & $\begin{array}{l}30 \text { oz. } \\
1024\end{array}$ & $\begin{array}{l}30 \mathrm{oz} . \\
1014\end{array}$ \\
\hline Solids, . . . . & 570 & 840 & 720 & 420 \\
\hline Urea, . & 218 & 188 & 228 & 121 \\
\hline Albumen, . & $\cdots$ & .155 & 134 & 39 \\
\hline
\end{tabular}

Thus we see that the solid matter in No. 1 and No. 2 is far above the average of health; that the quantity of urea is nearly as much below it, except in No. 2, where it is in excess; and that there is a large proportion of albumen, although diminishing with each specimen. It may fairly be presumed, $\mathrm{I}$ think, that the 
disproportion of these constituents was even more remarkable: at an earlier period of the disease, and for this reason I cannot avoid expressing my regret that I did not bestow more care upon it.

I have said that I did not see the patient after November 22nd, but Dr. Duke informs me that she continued to improve slowly up to November 25th, after which, for a few days, she seemed not so well; her intelligence was less, and she seldom spoke, but answered by a nod or a shake of the head; she retained the power of moving the leg, but not the arm. + Nov. 26 th. There was barely a trace of albumen in the urine. Nov, 30th. Dr. Duke informed me that our patient is again improving slowly. Dec. 12th. Up to this day the improvement had continued, slowly indeed, but quite marked. Her intelligence was restored, her bodily strength increased, her appetite better; in everything, save the impotence of the arm and leg, she was going on most favourably. During the morning she seemed very comfortable, and was talking cheerfully with her sister. At one o'clock she raised herself to a sitting posture in bed, and took some gruel, feeding herself with her left hand. As she finished, some remark of her sister's excited a tit of hearty laughter, after which she suddenly exclaimed, "Oh dear! Oh dear !" fell back insensible, and expired almost immediately.

Post-mortem Examination, Dec. 14, 2 P.M., forty-eight hours after death, by Dr. Duke and myself:-There were the usual marks of the gravitation of the blood, but no sign whatever of any putrefactive change; the body was in good condition, and a layer of fat, an inch thick, was found on cutting through the abdominal integuments. The head was first examined: there was no turgescence of the scalp, nor, when the skull was removed, was there anything abnormal detected about the dura mater. On removing this covering we found the superficial vessels moderately congested, except at one part of the anterior lobe of the right hemisphere, which was quite pale and bloodless, with. a slight effusion of serum beneath the arachnoid. But the most memorable fact noticed at this stage of our examination was, that every blood-vessel contained bubbles of air, alternating with globules of blood, giving to each vessel a beaded appearance, and this extended to very minute vessels, and to those in the division between the hemispheres. We traced the bloodvessels as minutely as we could with the naked eye, but could discover neither obstruction nor obliteration. The brain was then carefully removed; the upper portion of the spinal marrow and the nerves appeared quite healthy; there was no morbid appearance about the base of the brain; the pons varolii 
and the parts adjacent exhibited neither congestion externally, nor bloody points when cut into, nor any change in the firmness or appearance of their structure; the right hemisphere was healthy throughout, of its usual firmness and appearance, and, when divided, free from vascular points. In the anterior lobe of the left hemisphere, just about the anterior termination of the ventricle, we found the white cerebral substance, and, to a limited extent, the gray matter in the neighbourhood, reduced to a pulpy condition, about the density of gruel; the texture was completely destroyed for about an inch and a half in length by half an inch in breadth; the colour was very little changed, was certainly not redder than usual; posterior to the diseased part the tissue seemed quite natural; there was no hardness nor vascularity,-nothing, in short, to mark the transition from diseased to healthy structure. Again, in the posterior lobe, there was a similar, but smaller, spot of softening, without surrounding vascularity or hardness. We remarked, indeed, that the bloody points generally seen upon cutting through the substance of the brain were less numerous than usual. Dr. Lyons examined a portion of the softened part, and he found nothing but exudation corpuscles, with the debris of cerebral fibres; neither purulent nor serous infiltration; no other morbid appearance was discovered in the brain or cerebellum, and there was not above an ounce of serum escaped.

The lungs were free from adhesions, and perfectly healthy.

The heart was of the usual size, its walls of the ordinary thickness, and its cavities normal and empty; the auriculoventricular and aortic valves were complete, perfect, free from vegetations, and of the usual thinness.

On opening the abdomen we found no trace of peritonitis; the stomach, the greater portion of the small, and all the large, intestines, were perfectly healthy; in one part of the small intestines we found the coats stained of a reddish-brown colour, and the mucous membrane quite softened and pulpy.

The same reddish-brown colour extended to the contents of the pelvis; we found the uterus nearly reduced to its natural size (five weeks after delivery); its walls were of their natural thickness, and apparently healthy; the cervix was darkcoloured, and had still a bruised appearance; the cavity contained a thick, gelatinous, reddish-brown fluid, of which some had escaped through the vagina on to the bed; it had no putrid odour, but resembled not quite healthy menstrual fluid; the ovaries were small and healthy, but the broad ligaments and Fallopian tubes retained an unusually vascular appearance, and in the folds of the ligament was a cyst astarge as a grape. 
The kidneys were dense, and one much larger than the other; when cut into they exhibited great congestion, and from the divided tubes purulent matter escaped.

The other viscera were perfectly healthy.

1. I shall now give a summary of the foregoing cases, and make a few remarks upon the more important points connected with them. With regard to the numerical value of the cases, I should wish it to be understood that I consider the cases far too few to enable us to draw any very decided conclusions, although, as far as they go, the results are worth stating.

Of the 34 cases, in 22 the attack occurred during pregnancy; in 12 , either during or after labour.

In 23 cases where it is mentioned, I find that with 10 it was their first child; with 1 , the second; with 4 , the third; with 2 , the fourth; with 3 , the fifth; with 1 , the sixth; with 1 , the thirteenth; and 1 had several children, but the number is not specified.

Of the 34 cases, there were 17 of complete hemiplegia, and 1 partial; 4 of paraplegia, in 2 of which only one leg was affected; 6 of facial paralysis; 5 of amaurosis; and 3 of deafness; but in some of these latter local palsies were combined with the cases of hemiplegia. Of 14 cases of hemiplegia, in which the side affected is mentioned, I find that 11 were of the right, and 3 of the left side.

Of the 34 cases, 4 died.

It may be well, however, to consider these cases somewhat more closely, and for that purpose they may be divided into two classes, those which occurred during pregnancy, and those which were attacked during or after labour.

2. Of the 22 cases in which paralysis occurred during pregnancy, 12 were examples of hemiplegia; 1 of paraplegia, which had occurred previously; 4 of facial paralysis; 2 of amaurosis; and 3 of deafness. There is no regularity as to the period of gestation at which the seizure took place, for of 13 cases in which this is mentioned, in 1 it occurred in the second month; in 1 in the third or fourth; in 1 in the fifth; in 1 in the sixth or seventh; in 3 in the seventh; in 2 in the eighth; and in 4 in the ninth month; from which it would seem, upon the whole, that it is in the latter months that pregnant women are most liable to the attack.

Of 19 cases, 11 appear to have been cured before or by delivery, and in 8 the disease continued for a longer or shorter time afterwards.

Of the 20 cases, only 1 died, and in this case it is evident that death was rather owing to disease of the brain, of longer 
standing than the pregnancy, than to the paralysis which increased during that process; so that I do not think we can reckon it as impairing the comparatively innocuous character of these attacks during gestation.

In 3 cases only was the paralysis preceded by convulsions. In most of the cases it does not appear that there were any premonitory symptoms, little or no headach, or any other circumstance calculated to excite apprehension until the paralysis supervened. The characteristics of the palsy resembled yery closely those of similar attacks unconnected with pregnancy: the motor power was enfeebled or altogether lost; in some the sensibility was increased, diminished, or modified; but in others, $I$ infer from the silence of the reporter, that it was little, if at all, changed from its natural condition. The intellect seems to have preserved its integrity in all the cases. A peculiarity of great interest in many of these cases, and to which I shall revert by and by, is the presence of albumen in the urine, whenever that secretion was carefully examined.

3 . The second class, consisting of 12 cases, is characterized by the attack occurring during or after labour. It is remarkable that in 3 cases only (Cases xxirr., xxiv., xxv.) did the paralysis take place during labour, and of these, 2 were cases of convulsions; in all the others it not merely succeeded labour, but in most cases after an interval sometimes considerable: for example, in Case xxIII. it took place on the first day after delivery; in Case xxvir., two days afterwards; in Case xxxiI., three days; in Case xxxiv., seven days; in Cases xxvi., xXIX., XXXI., eight days; in Case $x \times x$., ten days; and in Case XxxIII., a month afterwards.

Of these 12 cases, 5 were cases of complete hemiplegia; in 1 only the arm was affected; 1 was a case of complete paraplegia; in 1 the right, and in 1 the left leg only was paralyzed; 2 were examples of amaurosis; 1 of facial paralysis; and in 3 only of the cases of hemiplegia the face participated in the attack. In Dr. Ley's very remarkable case, the paralysis of the motor power of one side was accompanied by loss of sensibility on the other. In some of the cases the sensibility was diminished, in others unaltered, but in none increased. The phenomena of the disease were not peculiar: in the majority of the cases the attack occurred generally without warning, and without any obvious cause. In 2 cases convulsions terminated in amaurosis, but in Mr. Forrest's case the paralysis preceded the convulsions, and during the latter, the paralyzed limbs shared in the convulsive movements.

The duration of the disease varied a good deal, the para- 
lysis gradually subsiding in most cases: in Case xxir., after several days; in Case XXIII., in six weeks; Case xxxI., recovered the use of the arm in a fortnight, but vision remained imperfect for some months; in Case XxxIV., in a month; in Cases XXVIII., XXIX., in two months; Case XXII., recovered the power of walking in two months, but was then attacked by another disease which proved fatal; Case xxvr. left the bospital without improvement.

In 3 cases death occurred: in Case $x \times x I I .$, on the fourteenth day, and in Case xxxIv., on the twenty-fourth day after the paralytic seizure. Dr. Ley does not mention on what day his patient died.

4. I have already alluded to the fact that in most of the cases the attack occurred without warning, and without apparent cause. Some cause there must be, of caurse, but it is much easier, in most cases, to say what it is not than what it is. For example, in none of these examples except one, did it appear to depend upon any external influence, - upon cold, exposure, violence, \&c.,-Dor upon mental distress; in few, if any, was there evidence of previous cerebral congestion, or disease of any other organ.

It has been suggested that the palsy may be merely the termination of convulsions, and certainly some of these cases would seem to support this view; but if this were generally true, we should find convulsions more frequently preceding the paralysis, and, also, we should meet with more cases of convulsions terminating in paralysis. Now, in all the cases I have quoted, a large majority exhibited no convulsive movements at all, and, on the other hand, of all the cases of convulsions related by Drs. Collins, and $\mathbf{M}^{\circ}$ Clintock and Hardy, there is not a single instance of such a termination; we must therefore refer both convulsions and paralysis to some common or different cause.

I have no doubt, as Dr. Romberg has observed, that in a number of cases, especially those which occur during gestation, the palsy is due to a reflex action from some organ or structure in a morbid condition, and in which the nervous system seems to be merely the channel of transmission, offering no central disorganization. In such cases the exciting cause may possibly be some injury or morbid condition of the generative organs, or perhaps merely a transient excitement, such as that of pregnancy. It is possible, also, that some of the instances occurring during gestation ought rather to be classed under the head of hysterical paralysis, as described by Drs. Laycock and Romberg, but it is not always easy to make the distinction. 
Obstruction of the arteries has been recently shown by Professor Simpsona, to be an occasional occurrence in childbed, either from arteritis, a coagulum, or a detached vegetation: and a degree of paralysis, may be the result; but inasmuch as the death of the limb, and ultimately of the patient, is the direct consequence of such an occurrence, the history of the cases I have quoted removes from them the suspicion of being thus caused.

It might naturally be supposed that the stress and exertions during labour which give rise to such great congestion of the face and head, by also occasioning congestion of the brain, might be considered one of the principal causes, but such a supposition is not borne out by facts, for, excluding the cases of convulsions, in only one case did the paralysis occur at the time of labour; in all the others it either supervened before labour, or subsequently, at a time when all such direct action must have ceased, and in some, after such an interval that we cannot suppose it even a remote effect of the parturient agony. On the other hand, when we remember the number of severe labours in which no such attack occurs, or compare its frequency with that of convulsions during labour, we can scarcely attribute much influence to this cause.

Again, as we have seen, paraplegia has been attributed to severe and prolonged labour, and to the consequent mechanical pressure upon the nerves and muscles of the pelvis, and at first sight this seems an adequate and feasible explanation, and of which no one could deny the possibility; yet so far as our cases are concerned it can hardly have been so, for in all but one the labour was natural, easy, and not prolonged: in the exceptional case the patient had been delivered by the forceps; moreover, the period at which it occurred was too distant to justify our attributing it to this cause in the other cases. On the other hand, if we recollect the number of severe, prolonged, and instrumental deliveries which take place, without any such result, no example being recorded by lors. Collins, $M \cdot C l i n t o c k$ and Hardy, or, with the exceptions I have quoted, in any of the reports of the British and foreign hospitals, so far as I am acquainted with them, I think we must also reject this peculiarity of labour as a necessary or frequent cause.

In two cases the attacks seem to have been connected with an anemic condition, consequent upon hemorrhage, either from the direct effect of a deficiency of the circulating fluid, or indirectly from the increased susceptibility of the nervous system, under these circumstances, to ordinary exciting causes. 
In another case paraplegia appeared to result from cold; but, in the majority of cases, as I have already observed, there was neither plethora nor anemia; neither exposure, want, injury, advanced age, mental distress, nor sudden shock; in short, there was no apparent cause.

5. Unfortunately for the cause of science, there are very few post-mortem examinations on record, from which we might decide with some degree of certainty upon the nature of the affection. In all the slighter and more partial cases, life is preserved, and when death occurs in the more severe instances, permission to examine the body cannot always be obtained. Of the four fatal cases I have here detailed, two only were examined: in these, and I doubt not, in the other two also, disease of the brain or its membranes existed. In Dr. Ley's case, he states that, "no positive disorganization of the brain could be detected. The ventricles, however, contained more than the usual serum; and there was found, more especially opposite to the original seat of pain, thickening and increased vaseularity of the membranes, with moderately firm adhesions in some parts; in others an apparently gelatinous, transparent, and colourless deposit, interposed between them." In short, there appears to have been an attack of partial meningitis, and the contrast between the peculiar train of symptoms to which it gave rise, and the absence of all symptoms except the palsy in Dr. Duke's case, is very interesting, when we remember the remarkable disorganization we discovered in the latter case.

Now in these cases we may fairly assume that the palsy and death itself were the result of the disease of the brain and its membranes, but to what are we to attribute the slighter and more numerous cases? Do they not appear to belong to the class described by Dr. Abercrombie, as "depending upon a cause which is of a temporary nature, and capable of being speedily and entirely removed."

6 . What is this temporary cause, producing so serious a disturbance, and yet scarcely, if at all, endangering life? May it be the one to which Dr. Latham refers, as observed " in those convulsions and apoplexies which appear and disappear, the chief circumstance which attracts our attention being albuminous urine"? At any rate it deserves our careful attention. Of the fact of the concurrence of albuminuria with certain affections of the nervous system during pregnancy and childbed, there can be no doubt whatever. Both Drs. Lever and Simpson have detected it in cases of convulsions during pregnancy and labour: the former observes:- "I have carefully examined the urine in every case of puerperal convulsions that has since 
oomezunder my notice, both in the Iuying-in; Charity af Guy?s Hospital, and in private practice, and in every case but:one, the unine has, been foupd to be albuminous, at the titae of the

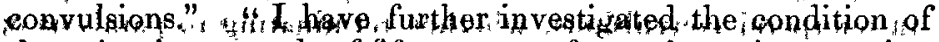
the rune in, upmands of fifty, women, from whom the secretion has beten drdamn, duringl abour, by the catbleter, care being token that none of the, vaginaly discharges, were, mixed with, this fluid;

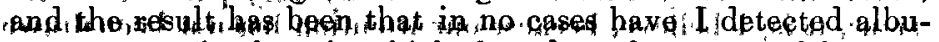

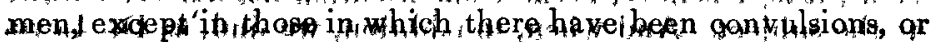

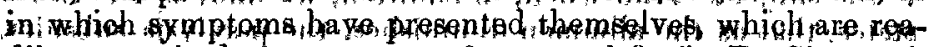

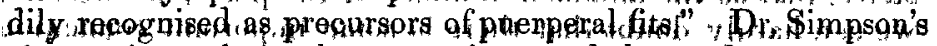
observations about the same time, and those af.mont abservers, Sabatier, Legroux, Richelot, and ot here, have confirmed the conclusions of Drw Lever, as to the presence of albumen, in the uringe in cases, of puerperal convulsions; so that no doubt now exista as to the fact, al though, we occasionally; meat cases, of ; con vulaions ; without albuminous , urine, and of albominunia without convuleiona ${ }^{a}$.

….Now, a\$ paralysigi in some casesi,occurs, in connexion with conxulsions, if not iss a consequencte of them, we might, not unnaturtally, expect albomen in the wine of suoh, patients, and acaosdingly, in a patient of Dr. Lever's, apd, in others, we find

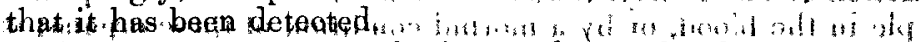

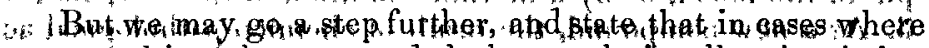

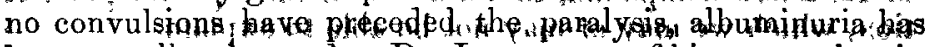

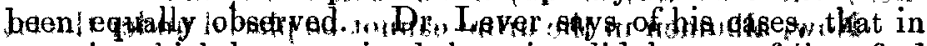
none in which he a amined the unine, did , he aver fail to find alburben, and the great experience of Professor Simpison is in close adcordance with this, may ibe seen iby that quatations I: have given, and by the casea with which, he has faveured

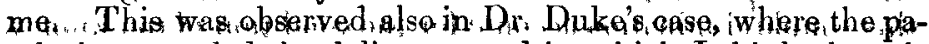
ralysis succeeded the delivery; and in which I think there is gnound for believing that the albumen, had diminished at the

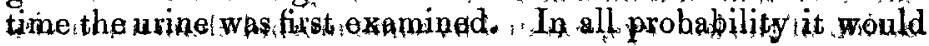

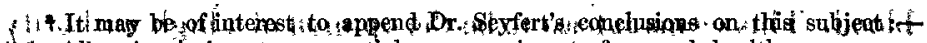

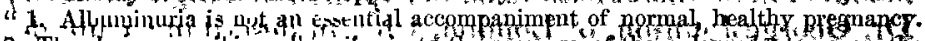
2. Tl-

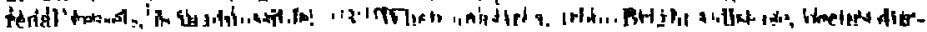

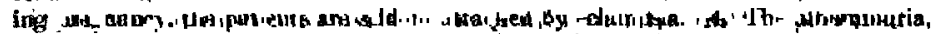

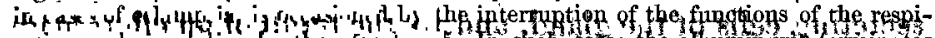
rati.n da... Ir. df

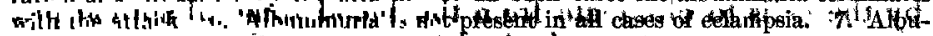

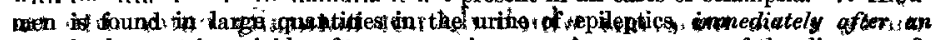
aftach, hut not puariably after every, seizure, or hevery gase of the disease, 8 . Frovided there be no Bright's disease, this atbuminuria among epileptics ceases soon after the convulsions, and only returns after the next attack." -Edinburgh Monthly Journal, Feb., 1854, p. 168 is 
have been detected in many others, had an investigation been made.

Thus we find that albuminuria may be a marked symptom in puerperal convulsions, whether terminating in paralysis or not; and in the palsy of pregnant and puerperal women, whether partial or complete, whether local or general: and if the observations are yet too few to draw any very positive conclusions, it is, I believe, because our attention has not been drawn to the subject. And when, in addition, we find, as Dr. Lever states, that as the albumen diminishes, the paralysis subsides, we can hardly doubt that there is some important connexion between them.

What then is the precise pathological significance of albuminuria? We may assume as established, that although it occurs in Bright's disease, it alone is no proof of the presence of that disease; but in the present state of our knowledge it is very difficult, perhaps impossible, to come to any very decided conclusion upon the matter. It is conceivable that an unusual, morbid, or noxious ingredient in the urine may be produced in either of three ways:-1. By simple elimination from the blood, in which it was present; 2. As the result of diseased action of the kidneys, excited either by some noxious principle in the blood, or by a morbid condition of these organs; or 3. As a new compound, the result of chemico-pathological action, which we may or may not be able to explain.

Now, albumen in the urine cannot be placed under the latter category, as it is not a new principle, but one already existing in the blood. Nor does it come under the first, for although it is possible that it might be eliminated from the blood in which it is present, it cannot be as a noxious element, nor would this simple elimination account for the condition of the kidneys or for the concomitant symptoms. So that it would appear this secretion of albumen must be owing to some disordered action of the kidneys, excited by some morbid element, in kind or degree, which they are endeavouring to separate from the blood. This seems at least to be the opinion of a high authority, Dr. George Johnson, of London, who, in describing acute desquamative nephritis, in which albumen is so largely secreted, observes, "that all the changes of structure commence in the secreting cells of the gland, and are the result of an effort made by the cells to eliminate from the blood some abnormal products, some materials which do not naturally enter into the composition of the renal secretion"a. This view is further con-

- Diseases of the Kidney, p. 105.

vot. XVII. No. 34, N. s. 
firmed by a post-mortem examination into the state of the kidneys themselves in albuminuria. Dr. Handfield Jones, in a rccent paper, has described three varieties: "The first is the condition of engorgement, such as is seen in those who die in the early stages of acute anasarca, or in that of dropsy succeeding scarlatina. The organ is enlarged, dripping with blood in every part; its tissue not destroyed, but many of the tubes are seen, under the microscope, to contain coagula of exuded fibrine, entangling blood globules, and more or less of epithelium." "The second form of diseased renal structure is that of the large, heavy, often mottled and pale kidney. In this there is no hyperemia, but rather the reverse state usually exists. The cut surface has not the appearance of healthy structure, and gives one the idea of some matter having been implanted among the natural constituents, so as to obscure them and to produce a confused aspect. The tubes are found impacted with epithelial matter, but not by any means constantly obstructed or blocked up, although they may be irregularly dilated, \&c." "The third variety of morbid change is that so familiar to ob. servation as the dwindled, granular kidney"a.

When we consider the temporary nature of the albuminuria in many of the cases of paralysis, we need have little doubt that the condition of the kidneys answers to the first variety here described, or that of extreme congestion, and this opinion is confirmed by the examination of Case xxxIv., in which we found a high degree of congestion, which had indeed passed into a more advanced stage. I think, therefore, that we may fairly assume the albuminuria is due to a congested state of the kidneys, and I confess I cannot but think that the explanation given by Dr. G. Johnson and others, that this congestion is excited by the effort to eliminate some noxious element from the blood, is more in accordance with our present knowledge than any other, yet I must not omit to mention that by some this congestion has been attributed to pressure of the gravid uterus upon the renal vessels. Dr. Seyfert, as we have seen, rejects this mechanical explanation, and seems to attribute the albuminuria to the eclampsia, in consequence of the interruption of the functions of respiration and circulation.

But, if the former theory be true, what is this morbid element, morbid in kind or degree? It is very difficult to answer this question. Dr. Simpson suggests that it may be an excess of urea or some morbid quantity or quality of caseine in the blood. Dr. George Johnson's observations seem to prove that

\footnotetext{
- Medieal Times and Gazette.
} 
in these cases, in addition to a change in the proportion of the normal constituents of the blood, of which the diminution of its albumen is one, there is always an excess of urea.

Then it may be asked, "to what is the effect upon the nervous system owing?" One can conceive that it may result either-1. From the continued presence of the noxious principle in the blood; or, 2. From the balance of the constituents of the blood having been destroyed; or, 3 . From the diseased condition of the kidney,- though to which of these we ought to attribute it, would be difficult to decide.

But at whatever conclusion we arrive with respect to these interesting points, I am sure all will agree with me, that, taking the circumstances into consideration, it is probable the kidneys play a more important part in these paralytic affections than has been suspected, and that the subject deserves more attention than it has received. For, we find that in cases of convulsions terminating in paralysis, we may have albuminuria; in paralysis before delivery, without convulsions, we may have albuminuria; in paralysis occurring after delivery, we may have albuminuria ; and further, that in the slightercases, both the convulsions and paralysis diminish with the decrease of the albuminous secretion. Whether therefore the paralysis be callsed by the state of the kidneys; or the renal congestion and paralysis be both the result of some morbid matter in the blood circulating through the system; it is clear that a new element may be added to those which have usually been considered as giving rise to paralysis.

7. Nor is this barren theory only, but, if it be true, it has a direct bearing upon practice, inasmuch as our attention ought not to be confined to the secondary affection of the nervous system in such cases, but must be directed to the relief of the renal malady, and to the restoration of the kidneys to such a state of efficiency as may enable them to remove the morbid constituents of the blood; and for our encouragement, we have seen that a diminution of albumen in the urine is fol. lowed by mitigation and cure of the paralysis. For the latter affection, blood-letting, general when the system will bear it, or local by means of leeches or cupping; blisters, purgatives, and mercury, are the remedies usually employed; these must be modified according to the condition of the patient, the circumstances of the attack, and the duration of the disease. When much blood has been lost during labour, bloodletting must be omitted, and we must confine ourselves to counter-irritation; perhaps a series of small blisters to the neck, down the spine, or along the limb, will be the best mode of proceeding. The 
patient's strength must ibe supported judicionsly by good diet, and it is quite possibje, that some stimulant, sueh as ammonia or camphovimaty deoi neisessary. When the paralysis has becomechronioy stryochnig or geal vanism may be found useful : and I believe Dr. Stokes Iras found igalvanic aoupuncturation very beneficiali in facial paralysisa

$\therefore$ The renali disonder rahould novex be breated by diuretics,

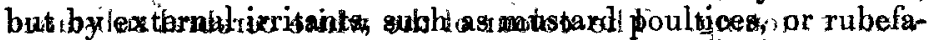

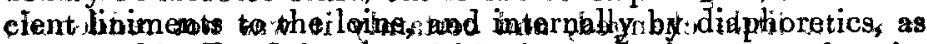

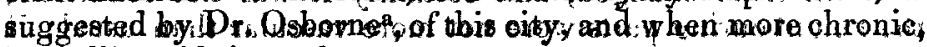
by gedlio acid; ifon, doc

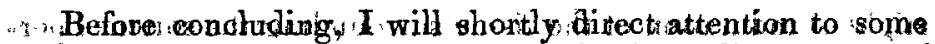
peculiarities in the case which was the inamediate cause of my bringing the subject forward. The points of poculiar in terest are, the state of the brain itself, the air in its vessels, the eondition of the kidneys, and the immediate cause of death. $\therefore$ 1. The Softening of the Brain.--Of the various pmemonitory symptoms mentioned by Abercombie, Iuallemand, Rostan, Durand-Fardel, Rowland, \&c., such as headach, diminished br madified sensation, los : or wealtening of ibtelligenee, idc., our patient exhibited none: up to the oncurrenoe tof the para; lysis she thad bea entinely free from eithet: local or general

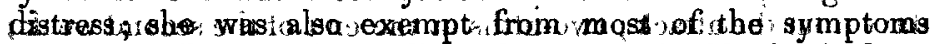

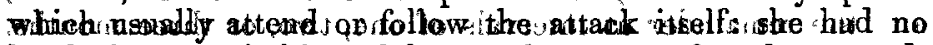
hebdadhi; tro twitching of the museleg, except for a fow seconds at the first aeizuna; no rigidity of the thexdrs; no disturbence of any special sense, or of sensation gevarally... The face had its natural placid expression; the eyes were intelligent, and sensitive (but not too much so) to light, and the ears to sound; her respiration was easy, and not hurried; her pulse was very quiek ; and either: her memory of some werds, on ber power of pronouncing them, was imperfeet; : but these, with the loss of power in the: arm, and leg, were the onlys zy mptoms when I sow her, and even these diminished after a time. Again, of all the rexcating causes usuadly enumerated,-otrch as hereditary predisposition, , itemperamen t, age,, occupation, shooks, mental

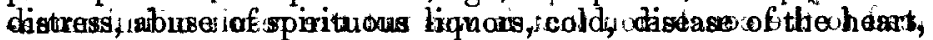

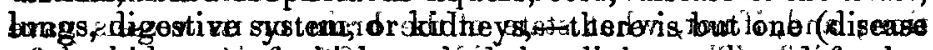

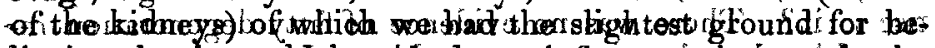

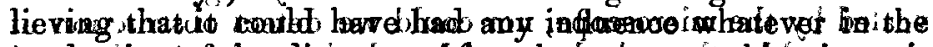

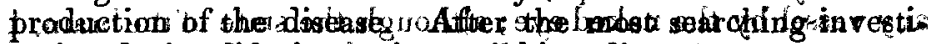

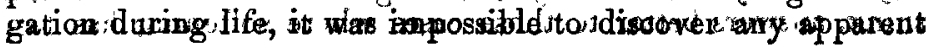

"On the Nature and Treatmentr of Dropsies; " 1837. 


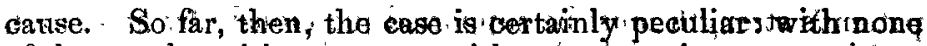
of the usual exorting causes ; without premonitory' gy mptoms'; and the actual symptoms l'mited to the loss of power, rownapid pulse, and a slighit tifficulty of nitteraneo; it seems tor ranswes better to Dr. Row land"s deseription of " latent softehing" than any other. Again, if we take the appearances on dissedtion! they differ a good deal from those in the ordinary formin of acnte softening:. The colour of the white cerebral substance was but little changed, and oertainly it was not reddened; the neighbouring parts were not mote rascular than iustal; if there was any difference, I should say that there were fewer red points than ordinary when cut across; there was not the slightest induration of the tissue surrounding the soned portion; nor had the latter any very defined limits, rbut seemed to pass gradually into the heal hy tiseve; there was ineitheninflitration of serum nor purulenti matter, ibut merel ys exudation oost

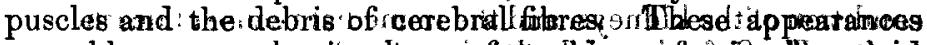

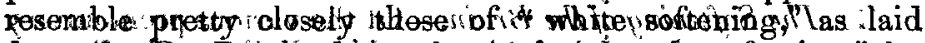

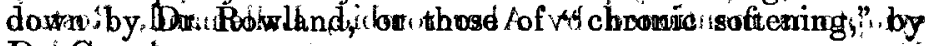
Dr. Otrosst:

$\therefore$ Lastly, the dination of the diseasen as somewhit probonged for a case of route softening. From the ébservations of Elatlez mand it appears that nearly one-half die within the finst? seven days from the attack; two-fifths at the end of the sedend weeks; and the remainder at intervals of one, two, or three months. Of 59 . cases of acnte softening, examined by Durand-Fardel; 11.terminated: fatally within the first forty-eight hours, 15 before the fiful day, 17 before the ninth day, 7 -from the ninth to the twentieth days and 9 from the wentieth to the thirtieth day. "As : tol the duration of chromio softening; Andral states that out of 105 persons; upwards of 16 survived the first; month more than 10 the second month, 7 reached the end of the third month, and 2 lived for three years.

i.What, then, was the nature of the softening in this case? and first was it inflammatory or non-inflammatory?: The his: story of the ease, the absence of the asual symptoms, and of the ordinary post-montem appearances in the brain, would rather lead to the conclesion that it was not the result of inflammation; and, if not, what state of the brain or its vessels gave riase to: it? .. There was na evidence of fatty degeneration revealed by the mioroscope; nor could we detect obstruction of any ressel by the naked eye; although the state of the brain, I think, answers better to those cases where softening has fol- 
lowed obstruction and atrophy, than to those in which it resulted from inflammation or fatty degeneration ${ }^{\mathbf{a}}$.

A second question may be raised, which it is not easy to answer, viz.:-Was the softening acute or chronic? did it occur before the paralysis; or was the latter due to some other cause, which, continuing to operate, produced also, after a time, the ramollissement?

2. Now let me draw attention to-the State of the Blood-vessels on the surface of the Brain.-With the exception of the anterior lobe of the right hemisphere of the brain, whose vessels were nearly bloodless, all the other vessels, large and small, which we could see, contained bubbles of air, alternating with globules of blood, giving to them a curious beaded appearance. This could not have been the result of injury in removing the calvarium, for then only the larger vessels near the track of the saw would have been affected, whereas the smaller ones within the division of the hemispheres exhibited the same appearance. Nor could it have been from ordinary decomposition, for no other part of the body showed the least sign of decay, and the brain is far from being the first to undergo this change. Did it, then, take place during life, or after death? In speaking of similar cases, Vogel is of the latter opinion, for he observes, that " vesicles of air in the vessels of the arachnoid, if they actually existed during life and whilst the circulation was yet proceeding, would, in accordance with the ordinary laws of physics, be conveyed with the blood to the heart"b. I confess myself quite unable to offer any explanation of the cause or the period of occurrence of this phenomenon.

3. The State of the Kidneys.-It will be remembered that we found them very highly congested, one of them very much enlarged; when divided, their substance was dripping with blood, and purulent matter escaped from their tubes, but was not collected in either large or small abscesses. What is the effect of inflammation and suppuration of the kidneys? Rokitanski, in his elaborate chapter on this subject, remarks that one or both kidneys may be affected : "In the latter case, especially," it is liable to terminate fatally, in consequence of paralysis of the renal function with typhoid symptoms, resulting from the detention of urea in the blood: this is frequently complicated with serous effusion into the ventricles of the brain, or into the pulmonary tissue, followed by putrescence; or if the inflammation reaches a certain degree of intensity, suppuration, or

2 Rowland on Softening of the Brain, p. 112.

b Pathological Anatomy, p. 31, Trans. 
an excessive retrograde process, or atrophy, may result; or lastly, the affection may become chronic"a. Yet in the case before us we see that inflammation and suppuration existed not only without giving rise to these effects, for there were neither typhoid symptoms, paralysis of the renal function, effusion, nor putrescence, but with symptoms of quite a different character.

Dr. Simpson has published some cases of puerperal nephri. tis, which are more to our purpose, as showing a connexion between that disease and convulsions. I shall give an extract from one:- " The lady had so perfectly recovered, after a labour which was quite natural, as to have been out at church, \&c. Seven weeks, however, after delivery, after some sudden and anomalous affections of sight and hearing, for thirty or forty hours previously, she was seized with most severe convulsions. Despite of free evacuations, \&c., they continued to recur from time to time, and proved fatal in three hours; the patient, during that time, never being perfectly sensible. The pelvis of each kidney was filled with a whitish, purulent-like matter, and its mucous lining membrane coated with large patches of adherent coagulable lymph, or false membrane; the ventricles of the brain were distended with serous fluid; the urine, when tested, presented no trace of albumen"b. Here, then, we have inflammation and suppuration of the kidneys giving rise to convulsions; and we have seen that the step from convulsions to paralysis is but a short one, for we have seen them co-existent, and both, probably, owing to the same cause, viz., some noxious element in the blood. It strikes me, therefore, as possible that the disease of the kidneys may have been the first morbid process in this case. Then if, as Mr. Henry Lee and others believe, pus in the blood disposes it to coagulate, and there is no fixed rule where this coagulation shall take place, or any relation between its origin and this local effect, it may be that coagulation, in consequence of the absorption of pus from the kidneys, took place in some of the minute vessels of the brain, causing obstruction and atrophy, or softening. But I merely throw out this as a possible explanation, without wishing to lay any stress on a mere hypothesis.

4. The sudden Death.-We have seen, not only that the life of the patient was for weeks preserved with this amount of disease going on, but that her condition gradually improved. Her intellect was as perfect as ever; her appetite was restored; and she could raise herself in bed and feed herself, with her

- Pathological Anatomy, vol. ii. p. 191. Sydenham Society's Edition.

b Edinburgh Monthly Journal, Sept., 1847, p. 213. 
left hand of course pt this poriod, after a fit of hearty laugh. ter, she fell back and died. What was the immediate cause of death? for ingthing was discovered to explain it: There was, neither hemprohage, mpl rapture of any organ w wor clot in the hearh alim \&ce , II

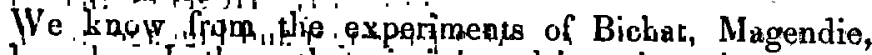
Piedlagnel, and others, thit air injectod into the veins proves

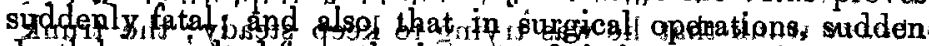

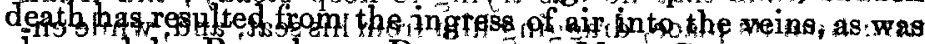

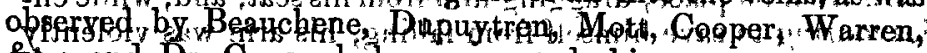

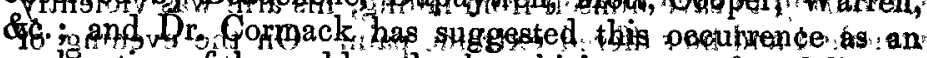
explangtion of the sudden deathe which, oecur after delivery: Byts in the presegt case wo have no evidence of the entry of an pud no obvions place at which it could enter ; for the uterus as we found, had recovered its patural size and condition. $\mathrm{Or}$ if the air in the vessels of the brain be taken as evidenoe, either of its entrance, ah, extra, or of decompesition, can we possihly assume that there was sufficient to paralyze the action of the heart Without offering any positive explanation, I canngt bat think that the termination of this case resembles more those cases of fatal syncope which occur after delivery; or that: state which Mr. Ghevallier termed "idiopathic asphy xia," than any other with which I am acquainted on those icares the patient makes same sudden exertionj bita up, or rises frombod; \& grand fls back lifelass or dying i, on oxamination, nothing is foppd to, explain this audden, temanation So in our case, w bilst thepe, was disease sufficient to extinguigh lifo, there was. nothing disgovered to account for the sudden death.

Arit. XII - On Dislocation forwards of thè Upper Extremity of the Raditis." By Wrician Tagrit, Senior Surgeon to Mercer"s Hospital.

DisLocation forwards of the upper extremity of the radius is an accident of rare occurrenee, often diffioult to diagnose, and: sonetimes foiling the best-directed efforts to reduce it teken wheg recont, Gooper, Cline ind other able surgeons, having failed in their attepptsi and in same instances whesteireduction

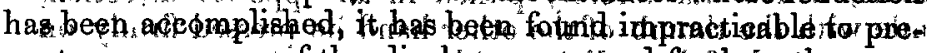

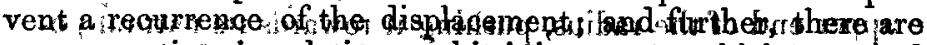

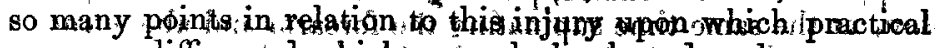
surgeons differ, and which ean only, bereaned up by an accumulated record of acos that $I_{1}$ m indubed to give an example of a dislocation forwards of the head of this ibone, Iately un- 